\title{
Symmetrical interaction of sex and expression in face classification tasks
}

\author{
Luis Aguado ANd ANa García-Gutierrez \\ Universidad Complutense, Madrid, Spain \\ AND \\ Ignacio Serrano-Pedraza \\ University of Kent, Canterbury, England
}

\begin{abstract}
Classification of faces as to their sex or their expression — with sex and expression varying orthogonally — was studied in three experiments. In Experiment 1, expression classification was influenced by sex, with angry male faces being classified faster than angry female faces. Complementarily, sex classification was faster for happy than for angry female faces. In Experiment 2, mutual interaction of sex and expression was also found when the participants were asked to classify top and bottom face segments. In Experiment 3, a face inversion effect was found for both sex and expression classification of whole faces. However, a symmetrical interaction between sex and expression was again found. The results are discussed in terms of configural versus feature processing in the perception of face sex and expression and of their relevance to face perception models that postulate independent processing of different facial features.
\end{abstract}

One of the main tenets of current models of face perception is that different types of facial information are processed through parallel, functionally independent routes. For example, the dominant functional model of face perception (Bruce \& Young, 1986) posits separate routes for the recognition of face familiarity or identity and for expression recognition. A neurologically based model has been proposed more recently by Haxby and colleagues (Haxby, Hoffman, \& Gobbini, 2000) that also incorporates different neural pathways for the processing of invariant (e.g., identity) and changeable (e.g., expression, eye gaze) aspects of faces. Independent processing of identity and expression has been postulated on the basis of the results of behavioral, neuropsychological, and functional brain-imaging studies, although the interpretation of these results has been questioned (Calder \& Young, 2005), and evidence has been accumulated that casts some doubts on the traditional parallel-route hypothesis.

\section{Interaction Between Identity and Expression}

Behavioral studies generally support some form of independence between identity and expression recognition. Ellis, Young, and Flude (1990, Experiment 2), for example, showed that familiarity judgments of a face were facilitated by previous familiarity classification of the same face. However, expression classification of a face was not facilitated by having previously identified its famil- iarity. Independence between expression and identity has also been found in matching tasks, in which familiarity facilitates identity but not expression matching (Young, McWeeny, Hay, \& Ellis, 1986). Neuropsychological studies of individuals with deficits in recognition of familiar faces (prosopagnosia) but preserved expression recognition (see, e.g., Bruyer et al., 1983; Tranel, Damasio, \& Damasio, 1988) have often been cited as evidence of the independence of identity and expression recognition. Finally, although occipito-temporal regions - and especially the lateral fusiform gyrus (the so-called fusiform face area, FFA) - have been consistently identified as mediating identity recognition, tasks requiring expression identification usually produce activation of the superior temporal sulcus (Winston, Henson, Fine-Goulden, \& Dolan, 2004).

There are, however, some results that suggest that identity and expression recognition might not be strictly independent. Using Garner's selective attention paradigm (Garner, 1976), Schweinberger and Soukup (1998) found results that showed an asymmetrical interference between expression and identity. They found, specifically, that the speed of identity judgments was independent of variation in expression, but that the speed of expression judgments was influenced by identity variation. Symmetrical influence between expression and identity, and the facilitation of expression classification of familiar - as compared with unfamiliarfaces has more recently been found by Ganel and Goshen- 
Gottstein (2004), also using Garner's paradigm. Moreover, the preservation of expression recognition in prosopagnosia seems not to be complete in many cases (see the critical review by Calder \& Young, 2005). Finally, the distinction between brain systems dedicated to the processing of identity and those involved in expression recognition might not be so sharp, since activation of the FFA has been found for both expression and identity recognition (Ganel, Valyear, Goshen-Gottstein, \& Goodale, 2005; Narumoto, Okada, Sadato, Fukui, \& Yonekura, 2001).

\section{Interaction Between Sex and Identity}

Another controversial issue in face perception is the relation between sex and identity. In the Bruce and Young (1986) model, sex and identity are processed by parallel systems, sex being processed by a system that does not store information of the face of specific individuals. However, sex is clearly an invariant aspect of the face and, as such, is highly correlated with identity. Although some studies have shown independence of familiarity and sex judgments (Ellis et al., 1990), several reports converge in suggesting that sex and identity are processed by a common system (Baudouin \& Tiberghien, 2002; Ganel \& Goshen-Gottstein, 2002; Goshen-Gottstein \& Ganel, 2000). For example, Ganel and Goshen-Gottstein (2002) found symmetric Garner interference effects for sex and familiarity judgments, with sex judgments being affected by variations in familiarity, and familiarity judgments being affected by variations in identity. Another result problematic for the parallel systems view is that the FFA has been found to be similarly activated by sex and identity judgments of faces (Dubois et al., 1999).

\section{Interaction Between Sex and Expression}

An unsettled issue in the face perception literature that will be the main concern of this article is the relationship between expression and sex. Findings consistent with independent processing of sex and expression have been reported by Le Gal and Bruce (2002, Experiments 2 and 3), using Garner's selective attention paradigm. In the control condition, the irrelevant dimension (sex or expression, depending on the specific task assigned to the participant) was kept fixed in each block, whereas in the orthogonal condition, sex and expression varied independently. The results showed an absence of differences between the control and orthogonal conditions - a finding that is usually taken as evidence of dimensional separability or independence (Garner, 1976). However, some details of the results were suggestive of possible asymmetrical interactions between sex and expression. In the correlated condition of the sex classification task, a faster reaction time (RT) to female surprised faces than to female angry faces and a faster RT to male angry faces than to male surprised faces was found. These results were paralleled by those in error percentage. Moreover, Le Gal and Bruce (Experiment 1) also found that explicit ratings of masculinity or femininity were influenced by the expression of the face, with surprised faces being rated as more feminine and angry faces being rated as more masculine.
Clearer evidence of asymmetrical interference between sex and expression has been reported by Atkinson, Tipples, Burt, and Young (2005). In the expression classification task, these authors found a slower RT in the orthogonal condition of Garner's paradigm than in the control condition. However, the two conditions did not differ in the sex classification task. As long as sex and identity are processed by a single system - as Haxby et al.'s (2000) model suggests - and given that identity has been found to influence expression classification (see, e.g., Ganel \& Goshen-Gottstein, 2004), this pattern of results might be interpreted as a further case of asymmetrical interaction between identity and expression. However, some results reported by Atkinson et al. point to a possible influence of expression on sex classification and suggest again that the interaction might not be completely asymmetrical. Specifically, when every combination of each relevant and irrelevant dimension was compared, Atkinson et al. found a marginally significant interaction of expression and sex that was due to slower classification of fearful than of happy faces as being male.

\section{Objectives of the Present Study}

In the present study, we tried to examine further the interaction between sex and facial expression. To this end, we used a simple face classification task in which male and female faces were classified as to their sex or as to their expression (happy or angry), with sex and expression varying orthogonally. Our main interest was not the comparison of different experimental conditions according to the specific relationship between sex and expression (as in Garner's paradigm), but to compare every combination of the relevant and irrelevant dimension in each classification task. Experiment 1 was an attempt to provide new evidence on sex and expression interaction. A pattern consisting of unidirectional sex to expression interference would further reinforce the asymmetrical character of the sex and expression interaction suggested by the results of Atkinson et al. (2005). However, the results already discussed, which show possible influences of expression on sex classification both in Le Gal and Bruce's (2002) and in Atkinson et al.'s studies, led us to expect that a symmetrical interaction might possibly be found. If - in contrast with the predictions from the parallel-route hypothesis - bidirectional influence from expression to sex and from sex to expression was found, this would indicate mutual dependence between these two dimensions of face recognition.

In Experiments 2 and 3, we tried to explore the possible perceptual basis of the sex and expression interaction. In Experiment 2, the participants were asked to classify the sex or the expression of upper and lower half faces, with the aim of testing the relative contribution of configural processing of the whole face and of local processing of parts of the face. Finally, in Experiment 3, the role of configural processes was explored by comparing sex and expression classification of upright and inverted whole faces. 


\section{EXPERIMENT 1}

\section{Experiment 1A}

In Experiment 1A, the participants were asked to classify a set of male and female faces that showed either angry or happy expressions. The experiment had two phases. The participants were asked first to perform a speeded classification task (sex or expression) and then, in the second phase, to rate sex or expression on a continuous 9-point scale. With these two tasks, we tried to examine the effects of sex and expression on speeded classification (as in both Le Gal \& Bruce, 2002, Experiments 2 and 3, and Atkinson et al., 2005, Experiments 1 and 2) and on a rating task (as in Experiment 1 of Le Gal \& Bruce, 2002). Sex and expression were varied orthogonally, with each model showing only one of the expressions, so as to prevent possible repetition priming effects based on the identity of the faces.

\section{Method}

\section{Participants}

Participants were 32 first- and second-year psychology students from the Universidad Complutense (Madrid, Spain), who participated in the experiment for course credit ( 26 females, 6 males; ages 18-31 years, $M=21$ ). Half of the participants were randomly assigned to the expression condition, and the other half to the sex condition.

\section{Apparatus and Stimuli}

The presentation of stimuli and the register of responses were controlled through the software E-Prime version 1.1. The program was run on a Pentium III computer with a 64-MB RAM memory, and the stimuli were presented on a VGA 17-in. monitor (refresh rate $60 \mathrm{~Hz}$ ). Participants were seated at a distance of $50 \mathrm{~cm}$ from the screen. Responses were registered through a five-key response box (PST Serial Response Box, 200A). Sessions were carried out individually in a soundproof, dimly lit room.

Stimuli were 32 pictures of human male and female faces showing either a happy or an angry expression. Twenty-nine of these pictures were taken from the Karolinska Directed Emotional Faces (KDEF) collection (Lundqvist \& Litton, 1998), and 3 were taken from the Ekman and Friesen (1976) collection (see Appendix A). Angry and happy expressions were chosen on the basis of prior results that suggested a possible interaction between sex and expression (e.g., a disadvantage for angry female as compared with surprised female faces in the sex classification task of Le Gal \& Bruce, 2002). Moreover, this disadvantage seems to be based on a well-defined facial measure that differentiates both face sex and face expression, brow-to-lid distance (see the General Discussion for more details on this facial measure). One measure of this facial feature is the ratio MaxA, calculated as the vertical distance between the corner of the eye at the outer canthus and the underside of the brow, divided by the diameter of the iris (Le Gal \& Bruce, 2002). In our face set, angry faces had a mean ratio MaxA of $0.72\left(M S_{\mathrm{e}}=0.064\right)$, and happy faces had a mean of $0.18\left(M S_{\mathrm{e}}=0.035\right)$, and the difference between these means was highly significant $[t(0)=6.26, p<.001]$.

There were 16 faces of males and 16 of females. Half the faces of each sex showed a happy expression, and the other half showed an angry expression. These faces were extracted from a bigger set that was evaluated in a prior pilot study by a sample of 30 psychology students. From this set, 32 faces with a minimum identification accuracy of .90 were selected (happy faces, $M=.96$; angry faces, $M=$ .93). Images were cut to conceal most of the hair and were equated in contrast energy ( $c_{\mathrm{RMS}}$, or root mean square contrast) (see Figure 1 and Appendix B for details of the image-processing procedure).

\section{Procedure}

Instructions and practice. The instructions for the classification phase were presented self-paced on the computer screen. Instructions described the task to be performed, and it was stressed that responses should be fast. Depending on the task condition, the participant was instructed that he or she had to identify either the expression - anger or happiness - shown by the face (expression classification task), or whether the face was male or female (sex classification task). The task was performed by pressing keys 1 and 5 of the response box. The assignment of keys to each alternative response was counterbalanced in each of the task conditions. Before the classification phase proper, eight practice trials were given. The faces presented during these trials were not presented again during the experimental phase.

Classification phase. During the classification phase, the 32 faces were presented once, with the order of presentation randomized independently for each participant. Faces appeared on the screen preceded by a fixation point (a white asterisk) that was presented at the center of the screen for $500 \mathrm{msec}$. The face stayed on the screen until either the participant gave a response or a maximum of 2,000 msec had elapsed. In the expression condition, the partici-
A

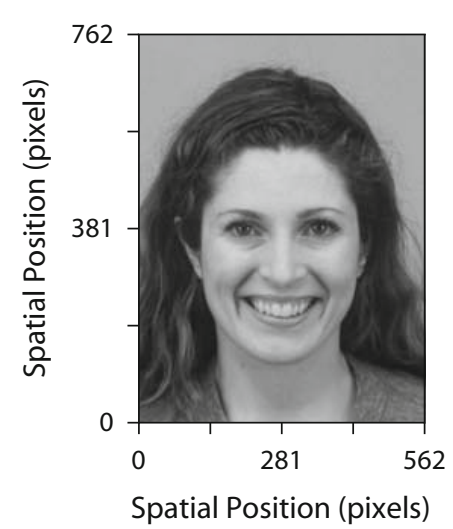

B

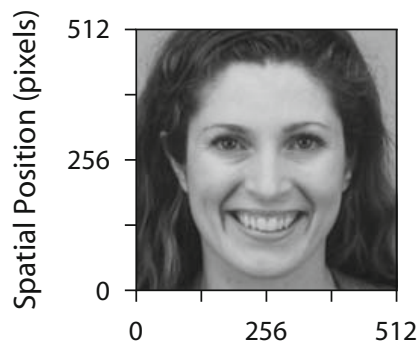

C $\quad C_{\mathrm{RMS}}=0.2178$

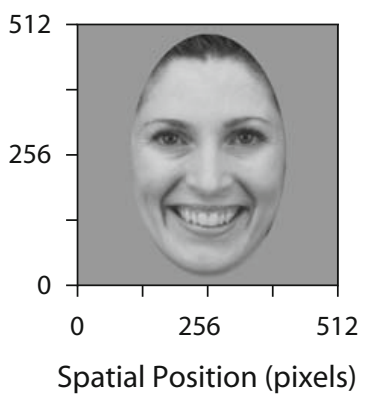

D $\quad c_{\mathrm{pMS}}=\mathbf{0 . 2 0 0 0}$

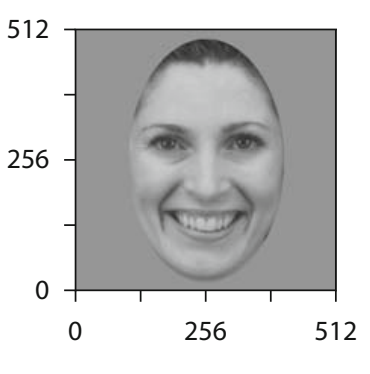

Figure 1. Procedure for constructing an image with a fixed $c_{\text {RMs. }}$ (A) Original image. (B) Cutout of the original image. (C) Image B with an oval window. (D) Image $C$ with desired $c_{R M S}(0.2)$ (to obtain $m$, the equation described in Serrano-Pedraza \& Sierra-Vázquez, 2006, was used). Note that the $c_{R M S}$ values of images $C$ and $D$ are different. 
pants were asked to classify the faces as showing happiness or anger. In the sex condition, the participants were asked to classify the faces as either male or female.

Rating phase. During this last phase, the 32 faces were again presented in random order. The participants were asked to rate each face on a 1-9 scale and were not given specific instructions as to response speed. In the expression condition, the participant had to rate the faces according to how angry or happy they appeared $(1=$ very angry, $5=$ neither angry nor happy, $9=$ very happy). In the sex condition, the participant had to rate the masculinity or femininity of the faces $(1=$ very masculine, $5=$ neither masculine nor feminine, $9=$ very feminine $)$. Faces stayed on the screen until a response was given or until a period of $5 \mathrm{sec}$ had elapsed. Responses were entered using the 1-9 number keys of the computer keyboard. By comparing the results of this phase with those of the classification phase, it would be possible to evaluate to what extent a possible interaction between sex and expression applies both to speeded, binary classification of sex or expression, and to explicit, graded evaluation of the faces along each of these dimensions. Knowing whether this interaction can be generalized to both test situations can be informative about its underlying mechanisms.

\section{Results}

In both this and the following experiments, data will be analyzed separately for the expression and the sex classification tasks. The data were submitted to a double analysis, in terms of error rates and RTs of correct responses. To test the generality of the RT results across participants and across items, a double analysis will be presented, first by participants and then by items.

\section{Classification Task: Error Rates}

Mean error proportion was $.01\left(M S_{\mathrm{e}}=.004\right)$ in the expression classification task and $.09\left(M S_{\mathrm{e}}=.01\right)$ in the sex classification task. The difference between tasks was significant $[t(30)=6.29, p<.001]$. Errors in the expres-
Table 1

Experiment 1A: Error Rates During the Classification Phase

\begin{tabular}{llllll}
\hline & \multicolumn{2}{c}{ Expression } & & \multicolumn{2}{c}{ Sex } \\
\cline { 2 - 3 } \cline { 5 - 6 } Stimulus & $M$ & $S E$ & & $M$ & $S E$ \\
\hline Angry-Female & .04 & .01 & & .26 & .03 \\
Angry-Male & .00 & .00 & .06 & .02 \\
Happy-Female & .02 & .01 & .02 & .01 \\
Happy-Male & .02 & .01 & .04 & .01 \\
\hline
\end{tabular}

sion classification task were not analyzed further. In the sex classification task, significant effects were found of face expression $\left[F(1,15)=45.31, p<.001, \eta_{\mathrm{p}}^{2}=.75\right]$, with more errors to angry than to happy faces, and of face sex $\left[F(1,15)=19.44, p=.001, \eta_{\mathrm{p}}^{2}=.56\right]$, with more errors to female than to male faces. Most importantly, a significant interaction between face expression and face sex was obtained $\left[F(1,15)=27.11, p<.001, \eta_{\mathrm{p}}^{2}=.64\right]$. Post hoc comparisons with the Bonferroni adjustment revealed significant differences between angry male and angry female faces $(p<.001)$, with more errors to angry female than to happy female faces. Mean error proportions for each combined sex and expression category are listed in Table 1.

\section{Classification Task: RTs}

In both this and the following experiments, only RTs for correct responses were analyzed. In the present experiment, no outliers (values outside a range of 200-2,000 msec) were identified. Expression and sex were classified at a similar speed, and mean RTs did not differ between tasks, with a mean of $616 \mathrm{msec}\left(M S_{\mathrm{e}}=35.34\right)$ for the expression task and of $601 \mathrm{msec}\left(M S_{\mathrm{e}}=25.69\right)$ for the sex task $[t(30)=0.26, p<.05]$. Mean RTs for each combined category of sex and expression are shown in Figure 2.

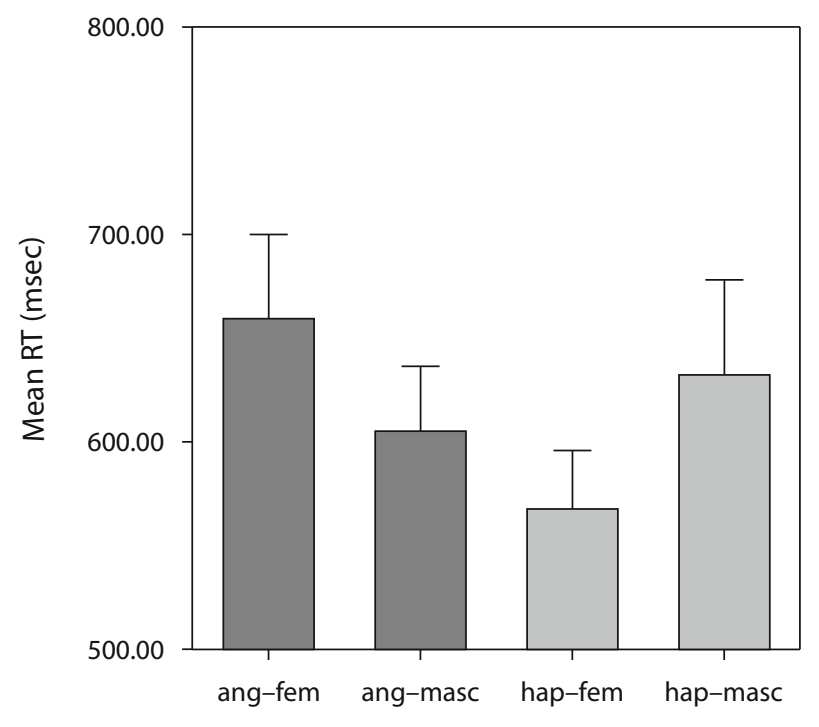

Stimulus

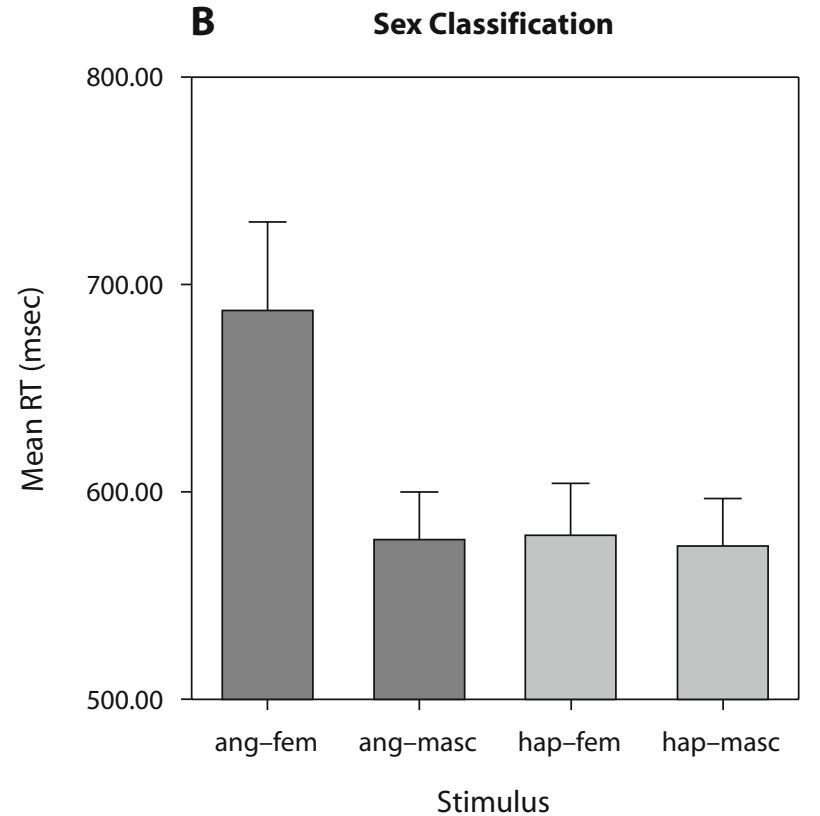

Figure 2. Mean reaction times (RTs) in the classification phase of Experiment 1A, for feminine and masculine angry and happy faces. Vertical bars represent SEM. 
Table 2

Experiment 1A: Evaluations During the Rating Phase

\begin{tabular}{|c|c|c|c|c|}
\hline \multirow[b]{3}{*}{ Stimulus } & \multicolumn{4}{|c|}{ Rating Task } \\
\hline & \multicolumn{2}{|c|}{ Expression } & \multicolumn{2}{|c|}{ Sex } \\
\hline & $M$ & $S E$ & $M$ & $S E$ \\
\hline Angry-Female & 2.58 & .34 & 5.85 & .24 \\
\hline Angry-Male & 2.41 & .37 & 3.34 & .62 \\
\hline Happy-Female & 7.41 & .35 & 6.61 & .57 \\
\hline Happy-Male & 7.34 & .31 & 3.60 & .55 \\
\hline
\end{tabular}

Note-Faces were rated on a 1-9 scale (expression task, 1 = very angry, 9 = very happy; sex task, 1 = very masculine, $9=$ very feminine) .

\section{Expression Task}

In the expression classification task, a significant main effect was found of face expression $[F(1,15)=6.05, p<$ $\left..05, \eta_{\mathrm{p}}^{2}=.28\right]$, the overall RTs to happy faces being faster than those to angry faces. However, this effect was qualified by a significant face expression $\times$ face sex interaction $\left[F(1,15)=11.47, p<.05, \eta_{\mathrm{p}}^{2}=.43\right]$. Post hoc comparisons revealed significant differences between male and female faces for both angry and happy expressions $(p \mathrm{~s}<.05)$. As can be seen in Figure $2 \mathrm{~A}$, angry female faces took longer to be classified as angry $(M=658$, $\left.M S_{\mathrm{e}}=41\right)$ than did angry male faces $\left(M=604, M S_{\mathrm{e}}=\right.$ 31 ) and, conversely, happy male faces took longer to be classified as happy $\left(M=632, M S_{\mathrm{e}}=45\right)$ than did happy female faces $\left(M=567, M S_{\mathrm{e}}=28\right)$.

\section{Sex Task}

In the sex classification task, significant effects were found of face expression $\left[F(1,15)=18.48, p=.001, \eta_{\mathrm{p}}^{2}=\right.$ $.55]$, of face sex $\left[F(1,15)=12.24, p<.05, \eta_{\mathrm{p}}^{2}=.44\right]$, and of the face expression $\times$ face sex interaction $[F(1,15)=$ 9.96, $\left.p<.05, \eta_{\mathrm{p}}^{2}=.39\right]$. Post hoc comparisons revealed that, as shown in Figure 2B, angry female faces were classified more slowly as female $\left(M=687, M S_{\mathrm{e}}=43\right)$ than were happy female faces $\left(M=579, M S_{\mathrm{e}}=24\right)(p=.001)$. However, the speed of classification of male faces was not influenced by expression.

\section{Classification Task: Analysis by Items}

The analysis by items for the expression task gave significant results of face expression $[F(1,28)=6.3, p<$ $\left..05, \eta_{\mathrm{p}}^{2}=.18\right]$ and, most importantly, of the face expression $\times$ face sex interaction $[F(1,28)=38.37, p<.001$, $\left.\eta_{\mathrm{p}}^{2}=.57\right]$. For the sex classification task, this analysis also confirmed a significant face expression $\times$ face sex interaction $\left[F(1,28)=8.44, p<.05, \eta_{\mathrm{p}}^{2}=.23\right]$.

\section{Rating Task}

An ANOVA with face expression and face sex as repeated measures variables was performed on ratings given on the rating phase, separately for each task condition. In the expression task, a significant effect of face expression was found $\left[F(1,15)=53.94, p<.001, \eta_{\mathrm{p}}^{2}=.77\right]$, whereas in the sex task, a significant effect was found of face sex $\left[F(1,15)=9.65, p<.05, \eta_{\mathrm{p}}^{2}=.40\right]$. In none of the task conditions were there significant effects of any of the interactions. Mean evaluations for each combined sex and expression category are listed in Table 2 .

\section{Experiment 1B}

The results for the sex condition of Experiment 1A showed that both speed and accuracy of face sex classification were affected by the expression shown by the face. However, since all participants evaluated the same set of images, it might be that these results were partly due to intrinsic differences in masculinity-femininity between the sets of happy and angry faces, independent of their expression. ${ }^{1}$ For example, it might be that the faces of women showing angry expressions were intrinsically less feminine than those posing happy expressions. In principle, the results of the rating phase seem to exclude such a possibility, since explicit masculinity-femininity ratings did not differ significantly between happy and angry faces. However, classifying the sex of a face is not the same as judging its masculinity or femininity, and conclusions cannot be safely generalized between tasks (see, e.g., Hoss, Ramsey, Griffin, \& Langlois, 2005). In sum, the argument that the results of Experiment $1 \mathrm{~A}$ reflected a true interaction between sex and expression would be further strengthened if it could be shown that the faces of the models showing angry and happy expressions in Experiment 1A were classified with similar accuracy, even when they showed a neutral expression. To this end, 12 additional participants (1st- and 2nd-year psychology students; 10 females, 2 males; mean age = 18 years) were given a speeded sex classification task in which they had to classify the neutral versions of the same models as those used in Experiment 1A. As in the previous experiment, each image was presented only once.

\section{Results}

Table 3 presents the error rates in the sex classification task of Experiment 1B. An ANOVA, with sex and expression shown by the model in Experiment $1 \mathrm{~A}$ as repeated measures factors, gave significant effects of face $\operatorname{sex}\left[F(1,11)=24.75, p<.001, \eta_{\mathrm{p}}^{2}=.69\right]$ of expression $\left[F(1,11)=7.21, p<.05, \eta_{\mathrm{p}}^{2}=.39\right]$, but not of the interaction $[F(1,11)=3.84, p>.05]$. In spite of the nonsignificant interaction, the error rates reported in Table 3 seem to indicate that the faces of the female models that showed an angry expression in Experiment 1A were especially difficult to classify. However, an inspection of the error rates corresponding to each picture revealed that the high error rate in the female angry condition was due to the fact that one of the female models showing an angry expres-

Table 3

Experiment 1B: Error Rates and Reaction Times (RTs, in Milliseconds)

\begin{tabular}{lccccc}
\hline & \multicolumn{2}{c}{ Error Rate } & & \multicolumn{2}{c}{ RT } \\
\cline { 2 - 3 } \cline { 5 - 6 } Stimulus & $M$ & $S E$ & & $M$ & $S E$ \\
\hline Angry-Female & $.22(.11)$ & $.03(.03)$ & & 689 & 28.8 \\
Angry-Male & .05 & .01 & & 675 & 34.7 \\
Happy-Female & .10 & .03 & & 674 & 29.8 \\
Happy-Male & .03 & .02 & & 631 & 23.6 \\
\hline
\end{tabular}

Note-Statistics after excluding the data corresponding to the KDEF model F16 are given in parentheses. 
sion in Experiment 1A-F16 from the KDEF set—was erroneously classified as male by all participants. The statistics corresponding to the female angry condition after excluding the data corresponding to this model are given parenthetically in Table 3. The same ANOVA performed after removing these data still gave a significant effect of face $\operatorname{sex}\left[F(1,11)=6.82, p<.05, \eta_{\mathrm{p}}^{2}=.38\right]$, but not of the face expression or of the interaction (both $p \mathrm{~s}>.05$ ). Although it might seem that the low accuracy of responses to this specific model influenced the results of the sex classification task in Experiment 1A, an inspection of classification accuracy for each individual item reveals that F16 was classified with $75 \%$ accuracy in that experiment. Although it might seem somewhat surprising, identification of the sex of this specific face was more difficult in its neutral than in its angry version. We also reran the statistical analysis of the results of the sex classification task of Experiment 1 after removing the data corresponding to the mentioned model, and found that the results remained unaltered. In conclusion, it seems that the results of the sex condition of Experiment $1 \mathrm{~A}$ cannot be attributed to intrinsic differences in masculinity-femininity of the faces of the models showing happy or angry expressions.

An ANOVA performed on RT data for correct responses did not reveal any significant effect, although there was a marginally significant trend suggesting slower classification of neutral faces of the models (both male and female) that showed angry expressions in Experiment $1 \mathrm{~A}$, as compared with those that showed happy expressions $(M=$ $695, M S_{\mathrm{e}}=20.3$ and $M=661, M S_{\mathrm{e}}=20.3$, respectively) $\left[F(1,11)=4.69, p=.053, \eta_{\mathrm{p}}^{2}=.29\right]$.

\section{Discussion}

The results of Experiment 1A showed a pattern of symmetrical interaction between sex and expression. In a speeded classification task, angry faces were classified faster as angry when the face was that of a male, and happy faces were classified faster as happy when the face was that of a female. Complementarily, when the faces had to be classified by their sex, female faces were identified significantly faster and more accurately when the expression shown was happiness. However, identification of male faces was not influenced by expression. As the complementary results of Experiment 1B with neutral faces of the same models show, this pattern of results cannot be explained by intrinsic differences in the perceived masculinity-femininity between the faces of the models showing happy or angry expressions (for example, the neutral faces of the females showing angry expressions being perceived as more masculine).

These results might be interpreted in at least two alternative ways. One is that expression and sex interact to determine the subjective impression caused by faces. For example, it might be that, due to social stereotypes, angry faces are subjectively perceived as more masculine, and happy faces as more feminine. Results consistent with this possibility have been reported by Le Gal and Bruce (2002) and by Hess, Blairy, and Kleck (1997). Le Gal and Bruce (2002, Experiment 1) found that when partici- pants had to rate the masculinity or femininity of male and female faces, surprised faces were judged as more feminine, and angry faces as more masculine. Complementarily, Hess et al. found that the emotional intensity ratings of happy and angry faces were influenced by the sex of the model - expressions of anger being judged as more intense when shown by men, and expressions of happiness being judged as more intense when shown by women. However, the results obtained in the rating phase of the present experiment are apparently inconsistent with this interpretation, since an interaction between expression and sex was not found in either of the two tasks. For example, when participants were asked to rate the sex of the faces, angry males were not rated as more masculine than happy males, and happy females were not rated as more feminine than angry females. This result suggests a second explanation of the interaction between sex and expression. Specifically, this interaction might have taken place at the level of the processing operations that lead to the identification of faces as angry-happy or malefemale, without influencing the subjective intensity of the expression observed or the masculinity or femininity of the face. However, it might have been that although they were rating the faces, the participants tried deliberately to counteract the influence of the irrelevant dimension. For example, although an angry female face might at first impression appear a bit male-like, one can compensate for this impression when rating sex and up-regulate deliberately the femininity rating. In fact, an inspection of RTs for rating responses in the sex task suggests a sex $X$ expression interaction effect similar to that observed in the classification phase, which was confirmed by statistical analysis $[F(1,14)=9.17, p<.05]$. Specifically, the participants took longer not only to rate angry female as opposed to happy female faces, but also to rate happy male as opposed to angry male faces, which seems to suggest an even more complete interaction than that obtained with classification times, where differences were found only in the classification of female faces.

The results of the classification phase of Experiment $1 \mathrm{~A}$ stand in clear contrast with those obtained by Le Gal and Bruce (2002, Experiments 2 and 3), who found evidence of the independence of sex and expression using Garner's selective attention paradigm with faces showing surprised and angry expressions. However, when comparing the different combinations of the two dimensions, these authors also reported some results suggestive of an interaction between sex and expression. This notwithstanding, a potentially important procedural difference between Le Gal and Bruce's procedure and ours is that their procedure involved giving the participants hundreds of trials, with each particular face being presented several times. In contrast, each face was presented only once during the classification phase of our Experiment 1A. This is important, because repetition of the faces might have compensated, through perceptual learning and repetition priming, for any possible interaction between sex and expression that might have been present with fewer presentations. 
Similar to the results reported by Atkinson et al. (2005) with Garner's paradigm, we found a clear influence of sex on expression classification. The classification task used in our Experiment 1A is, in fact, equivalent to the orthogonal condition of Garner's paradigm, and our results can thus be taken as a replication of those of Atkinson et al. - at least in the simple and more general sense of showing an influence of the sex of the face on expression classification. However, a new finding is that in the present experiment, clear evidence of the complementary effect was also foundthat is, an influence of expression on sex classification. This finding does not necessarily contradict the findings of Atkinson et al. First, instead of happy and angry faces, they used happy and fearful faces as stimuli, and there might be differences in the extent to which different expressions influence sex classification. For example, different emotional expressions may alter to a different degree the features characteristic of each sex, so that only some of them will interfere with sex classification. This is probably the case for angry expressions, which alter one of the more reliable features for sex discrimination, brow-to-lid distance (Burton, Bruce, \& Dench, 1993; Campbell, Wallace, \& Benson, 1996; see the General Discussion for further comments on the possible role of this feature). In fact, we found significant differences in sex classification only in the case of female faces, with more errors and slower RTs to angry expressions than to happy expressions. Given that browto-lid distance is usually bigger in females, and that angry expressions reduce this distance (Ekman \& Friesen, 1978; Gosselin, Kirouac, \& Doré, 1997), a straightforward explanation is that angry expressions increased the time needed to classify the sex of female faces. Second, there were, in fact, some suggestions of an influence of expression on sex classification in Atkinson et al.'s results. First, in their Experiment 1A, male happy faces were classified faster than fearful male faces in the sex classification condition, with the sex $\times$ expression interaction approaching significance. Moreover, in their Experiment 2, with morphed faces of varying difficulty, RTs were significantly faster in the control than in the orthogonal condition for faces of the highest difficulty level.

\section{EXPERIMENT 2}

Studies with different paradigms have suggested a principal role for configural processing in both sex and expression classification. For example, the face inversion effect (Yin, 1969) - that is, a decrement in performance with inverted, as opposed to upright, faces that is usually observed in face recognition - has been found in both expression and sex classification tasks (Bruce et al., 1993; McKelvie, 1995). A second configural phenomenon-the composite effect (Young, Hellawell, \& Hay, 1987), consisting in the fusion of the top and bottom halves of different faces into a perceptually new face- has also been shown in these tasks (Baudouin \& Humphreys, 2006; Calder, Young, Keane, \& Dean, 2000). However, some results from studies that presented different parts of the face to the participants point to a complementary role of local processing in expression and in sex classification, based on individual features or on second-order relations between features (Brown \& Perrett, 1993; Ellison \& Massaro, 1997). Furthermore, presentation of isolated facial parts has been used previously to assess the role of configural processing in the perception of face expression in studies with schematic faces (Fox et al., 2000; Tipples, Atkinson, \& Young, 2002). While the results of Fox et al.'s Experiment 4 showed that downward curves (resembling angry or sad mouths) were detected faster than straight or upward curves (resembling neutral and happy mouths, respectively) only when other facial features (eyes and nose) were added, those of Experiment 5 in Tipples et al.'s report showed that schematic faces with $\mathrm{V}$-shaped eyebrows were detected faster than faces with inverted V-shaped eyebrows only when eyes were added. The results of Fox et al. are of special relevance in the present study, since they suggest that the ability of different mouth shapes to convey an expressive meaning relies on the presence of additional features from the upper face.

In Experiment 1A, we found a symmetrical interaction between expression and sex in a speeded classification task in which the expression or the sex of whole faces had to be classified. Experiment 2 was an attempt to evaluate to what extent this interaction is based on configural processing of the whole face or on local processing of parts of the face. To this end, the participants were presented with the top- and bottom-half segments of the same faces as those used in Experiment 1A and were asked to classify them as to their expression or their sex. To the extent that the interaction between sex and expression found in Experiment 1A was based on configural processing of the whole face, it should disappear or be significantly altered by face segmentation. The choice of top and bottom face portions was based on previous evidence from studies with real faces, showing that relevant information for the classification of sex and expression is contained in the upper and the lower face when seen in isolation (Brown \& Perrett, 1993; Calder et al., 2000).

\section{Method}

\section{Participants}

Thirty-two first- and second-year psychology students ( 24 female, 8 male; ages $17-38$ years, $M=19.5$ ) participated in the experiment for course credit.

The apparatus and general experimental conditions were similar to those of Experiment 1A.

\section{Stimuli}

The same set of faces as that used in Experiment 1A was used in this experiment. The specific stimuli for Experiment 2 were prepared by dividing each picture into top and bottom segments. Each face was cut along a horizontal line through the bridge of the nose. Stimuli were presented so that upper and lower face segments appeared above and below the position of the fixation point, respectively.

\section{Procedure}

The general procedure was similar to that of Experiment 1A, with the exception of the rating phase, which was omitted in the present experiment. The classification phase was divided into four blocks of 16 trials each. In each block, eight angry and eight happy faces were presented, four of each sex. Half of the trials in each block showed top face segments, and the other half showed bottom face segments, with the same proportion of sex and expression. The stimuli were 
Table 4

Experiment 2: Error Rates

\begin{tabular}{|c|c|c|c|c|}
\hline \multirow[b]{3}{*}{ Stimulus } & \multicolumn{4}{|c|}{ Face Segment } \\
\hline & \multicolumn{2}{|c|}{ Bottom } & \multicolumn{2}{|c|}{ Top } \\
\hline & $M$ & $M S_{\mathrm{e}}$ & $M$ & $M S_{\mathrm{e}}$ \\
\hline
\end{tabular}

Expression Classification

$\begin{array}{lllll}\text { Angry-Female } & .03 & .01 & .05 & .01 \\ \text { Angry-Male } & .05 & .02 & .03 & .01 \\ \text { Happy-Female } & .02 & .02 & .03 & .01 \\ \text { Happy-Male } & .02 & .01 & .03 & .01\end{array}$

Happy-Male

Sex Classification

$\begin{array}{lllll}\text { Angry-Female } & .27 & .04 & .37 & .05 \\ \text { Angry-Male } & .17 & .05 & .05 & .04 \\ \text { Happy-Female } & .22 & .05 & .07 & .03 \\ \text { Happy-Male } & .01 & .01 & .07 & .03\end{array}$

distributed throughout the blocks so that on a specific block, only one face of each identity was presented. Half of the participants performed an expression classification task, and the other half a sex classification task.

\section{Results}

\section{Error Rates}

The error proportions for each combination of sex, expression, and face segment are listed in Table 4. Mean error proportion was significantly higher in the sex classification task $\left(M=.14, M S_{\mathrm{e}}=.016\right)$ than in the expression classification task $\left(M=.03, M S_{\mathrm{e}}=.016\right)[t(30)=6.48$, $p<.001]$. No further analysis of error rates was performed in the expression task. Mean error rates for each combined sex and expression category in each face segment are listed in Table 4. In the sex classification task, significant main effects were found of face expression $[F(1,15)=68.6, p<$ $\left..001, \eta_{\mathrm{p}}^{2}=.82\right]$, with more errors to angry than to happy faces, and of face sex $\left[F(1,15)=16.09, p<.05, \eta_{\mathrm{p}}^{2}=\right.$ $.51]$, with more errors to female than to male faces. These effects were qualified by a significant three-way face expression $\times$ face sex $\times$ face segment interaction $[F(1,15)=$ 21.93, $p<.000, \eta_{\mathrm{p}}^{2}=.59$ ]. Post hoc tests carried out to explore this interaction revealed significantly higher error rates for male angry lower faces $\left(M=.17, M S_{\mathrm{e}}=.04\right)$ than for male lower happy faces $\left(M=.01, M S_{\mathrm{e}}=.01\right)(p=$ $.001)$, and for upper female angry faces $\left(M=.37, M S_{\mathrm{e}}=\right.$ $.94)$ than for upper female happy faces $\left(M=.07, M S_{\mathrm{e}}=\right.$ .02) $(p<.001)$.

\section{RTs}

Figure 3 shows mean RTs for each combination of sex and expression, corresponding to the top- and bottomhalf face segments in each task condition. Mean RTs in the expression and sex classification tasks were $793 \mathrm{msec}$ $\left(M S_{\mathrm{e}}=53\right)$ and $741 \mathrm{msec}\left(M S_{\mathrm{e}}=40\right)$, respectively. The difference between these RTs was not significant $[t(30)=$ $0.77, p>.05]$. An ANOVA with face segment, face expression, and face sex as repeated measures factors was carried out on RTs, separately for each task condition. In the expression classification task, no significant effects were found of face expression or of face sex. However, a significant main effect of face segment was found $\left[F(1,15)=5.5, p<.05, \eta_{\mathrm{p}}^{2}=.26\right]$, with faster RTs to bottom segments than to top segments. This effect was qualified by a significant face segment $\times$ face expression interaction $\left[F(1,15)=34.48, p<.001, \eta_{\mathrm{p}}^{2}=.69\right]$. Exploration of this interaction by post hoc tests revealed

\section{A Expression Classification}

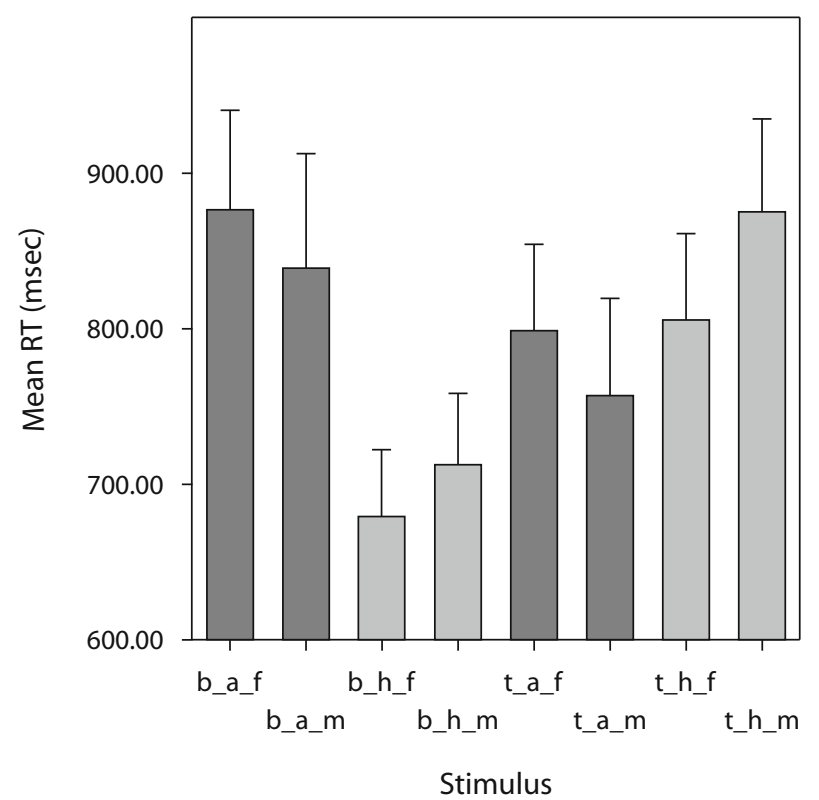

B

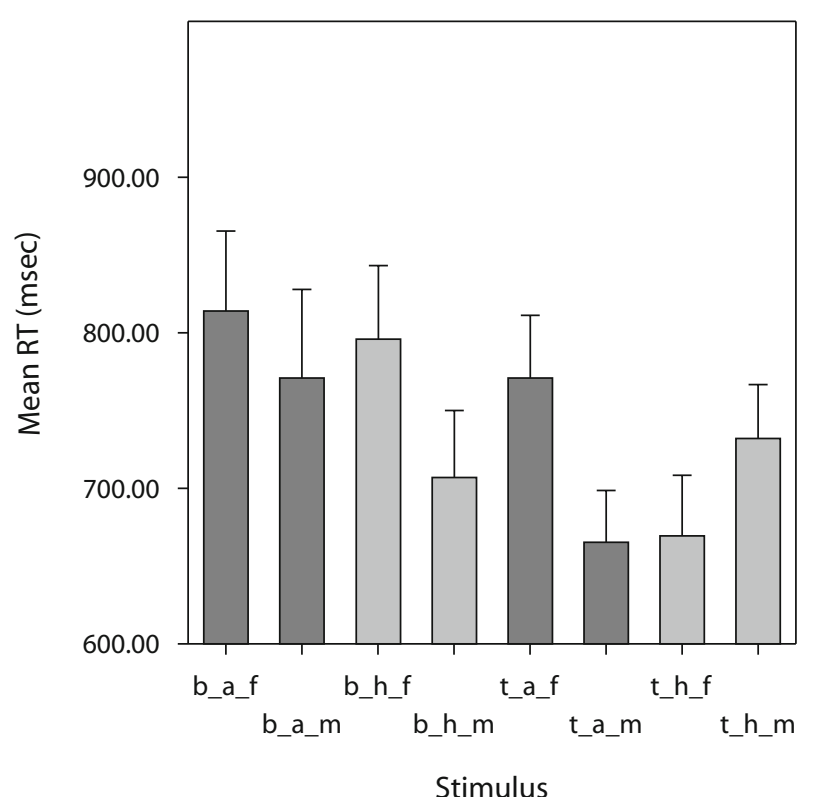

Figure 3. Mean reaction times (RTs) in Experiment 2 for feminine and masculine angry and happy faces. Vertical bars represent the $S E M$. b, bottom face; $t$, top face; a, angry; $h$, happy; f, feminine; $m$, masculine. 
that anger was recognized faster in the upper than in the lower face, but that happiness was recognized faster in the lower than in the upper face, with significant differences between the upper and the lower face for both expressions $(p \mathrm{~s}=.001)$. Finally, and most importantly, a significant face expression $\times$ face sex interaction was also found $\left[F(1,15)=12.62, p<.05, \eta_{\mathrm{p}}^{2}=.45\right]$. Post hoc analyses revealed significant differences between happy male and female faces, with female faces being recognized faster as happy $\left(M=742, M S_{\mathrm{e}}=47\right)$ than male faces $(M=794$, $\left.M S_{\mathrm{e}}=50\right)(p<.05)$, and a marginally significant difference between angry female and male faces, with male faces being recognized faster as angry $\left(M=798, M S_{\mathrm{e}}=\right.$ $67)$ than female faces $\left(M=838, M S_{\mathrm{e}}=58\right)(p=.067)$.

In the sex classification task, significant main effects were found of face segment $[F(1,15)=13.05, p<.05$, $\left.\eta_{\mathrm{p}}^{2}=.46\right]$ and face sex $\left[F(1,15)=15.47, p<.001, \eta_{\mathrm{p}}^{2}=\right.$ $.50]$. A significant face segment $\times$ face sex interaction was found $\left[F(1,15)=4.89, p<.05, \eta_{\mathrm{p}}^{2}=.24\right]$. Post hoc comparisons revealed significantly faster recognition of females from top than from bottom segments of the face $(p<$ $.001)$ and a similar but not significant trend $(p=.08)$ for male faces. The most important result of this experiment was, however, the significant triple face segment $\times$ face expression $\times$ face sex interaction $[F(1,15)=14.22, p<.05$, $\left.\eta_{\mathrm{p}}^{2}=.48\right]$. Post hoc comparisons performed to explore this interaction showed that emotional expression influenced the speed of sex classification only when the top segment of the face had to be judged. Specifically, although female upper faces were recognized faster as females when the expression was happiness, male upper faces were recognized faster as males when the expression was anger $(p \mathrm{~s}<.05)$. However, a nonsignificant trend for male lower happy faces being recognized faster than lower angry male faces was observed $(p=.09)$ that is consistent with the equivalent significant difference found for error data.

\section{Analysis by Items}

The results of the analysis across participants were mostly confirmed by the analysis across items. In the expression classification task, this analysis gave significant results of face expression $\left[F(1,56)=4.47, p<.05, \eta_{\mathrm{p}}^{2}=\right.$ $.07]$, of the face segment $\times$ face expression interaction $\left[F(1,56)=27.9, p<.001, \eta_{\mathrm{p}}^{2}=.33\right]$, and of the face expression $\times$ face sex interaction $[F(1,56)=7.25, p<$ $\left..05, \eta_{\mathrm{p}}^{2}=.11\right]$. In the sex classification task, significant effects were found of face segment $[F(1,56)=5.67, p<$ $\left..05, \eta_{\mathrm{p}}^{2}=.09\right]$ and of the triple face segment $\times$ face expression $\times$ face sex interaction $[F(1,56)=6.8, p<.05$, $\left.\eta_{\mathrm{p}}^{2}=.10\right]$.

\section{Discussion}

In Experiment 2, the symmetrical interaction between sex and expression obtained in Experiment 1A was replicated, this time with top- and bottom-half face segments. Classification of emotional expression was influenced by the sex of the face, and complementarily, classification of sex was influenced by the expression shown by the face. A relevant aspect of this interaction is that it was only partially modulated by the segment of the face. Specifically, the interaction was equivalent for top and bottom face segments in the case of the expression task, but it differed between segments in the sex task. Again, as in Experiment 1A, higher error rates were observed in the sex classification task. Overall, angry expressions had the biggest impact on sex classification, especially in the case of upper female faces, although a significant but smaller drop in performance was also observed for lower angry male faces.

The analysis of RTs of correct responses gave a different pattern for the expression and the sex classification task. First, in the expression task, an interaction was found between the expression and the segment of the face, with faster recognition of happiness in the bottom segment and of anger in the top segment. This result replicates previous reports showing that different emotional expressions are differently recognizable in the upper and the lower face and that, specifically, happiness is more accurately recognized in the lower face, and anger in the upper face (Bassili, 1979; Calder et al., 2000). Sex recognition was also influenced by the segment of the face, although in this case, a trend was found for faster recognition of both sexes from top segments. This result is consistent with previous reports showing that when different parts of the face are seen in isolation, the eye region-including eyes and brows - is the most discriminative for sex classification (Brown \& Perrett, 1993).

A second difference between the expression and the sex classification tasks was that although sex and expression interacted in both cases, the details of this interaction differed between tasks. In the expression task, these details basically replicated the results of Experiment 1A with whole faces, with the only exception that the difference between happy and angry male faces reached only marginal statistical significance in the present experiment. Moreover, the interaction between sex and expression was not modulated by the specific face segment shown and applied equally to both segments. When measured in terms of RTs, the interaction between sex and expression applied only to top face segments in the sex classification task. The classification of top female faces was faster for happy than for angry faces. Conversely, the classification of top male faces was faster for angry than for happy faces. These results are comparable to those of Experiment 1A with whole faces. However, when bottom face segments were classified, a nonsignificant trend emerged for male faces to be recognized faster when the expression shown was happiness - a trend that is exactly the opposite to that found in Experiment 1A.

The more general conclusion that can be extracted from the results of Experiment 2 is that sex and expression interact even in the absence of the context of the whole face. This result indicates that configural processing of the whole face is not necessary for this interaction to occur, although the influence of this kind of processing when the interaction occurs with whole faces cannot be excluded. The differences between Experiments $1 \mathrm{~A}$ and 2 in the details of the interaction between sex and expression sug- 
gest that at least some aspects of this interaction might be based on different factors in both whole and segmented faces. The discussion of the possible perceptual basis of this interaction and its underlying mechanisms will be deferred until the General Discussion.

\section{EXPERIMENT 3}

The face inversion effect (Yin, 1969) has been found in several face classification tasks and has been taken as an indicator of the special character of face processing (for a review, see Valentine, 1988). This effect is usually interpreted as being due to the disruption of configural processing, although the exact meaning of "configural" has been a matter of debate. Holistic processing - that is, processing of the face as a template or as a gestalt-is the most extreme form of nonlocal processing (Tanaka \& Farah, 1993). A distinction between two other forms of configural processing was proposed by Diamond and Carey (1986), who differentiated first-order spatial information (spatial relations between parts of the face, such as eyes above the nose and nose above the mouth) from second-order relations, referring to the relative size of spatial relations (e.g., eyes-nose or nose-mouth distance). Leder and Bruce (2000; Leder, Candrian, Huber, \& Bruce, 2001) have reported findings that point to the disruption of the processing of this kind of relational information as the main determinant of the face inversion effect, although there is evidence that other forms of configural processing are equally disrupted by inversion (see Maurer, Le Grand, \& Mondloch, 2002).

A necessary role for holistic processing in the interaction between sex and expression can be excluded, since the results of Experiment 2 showed this interaction with top and bottom face segments presented in isolation. However, these half faces still contain information that can support second-order relational processing based on distances between facial features. In Experiment 3, the possible role of relational processing as a determinant of the interaction between sex and expression was tested by comparing the classification of upright and inverted faces. To the extent that the interaction observed in Experiments 1 and 2 relies on this kind of processing, it should be reduced by face inversion. If, on the other hand, the interaction was based on properties not disrupted by inversion - such as variations in feature shape (Maurer et al., 2002) — it should still be present with inverted faces.

\section{Method}

\section{Participants}

Thirty-eight first- and second-year psychology students (30 female, 8 male; ages $17-30$ years, $M=20.2$ ) participated in the experiment for course credit. Twenty participants performed an expression classification task and 18 performed a sex classification task. The general procedure of this experiment was similar to that used in Experiments 1A and 2. The same set of faces was used. The experiment had two phases: one in which the faces were presented upright, and another in which the faces appeared inverted. Each phase had two blocks of 32 trials. On each of these blocks, the 32 images were presented, so the participants saw the same set of faces four times: two in upright and two in inverted presentation. The order of the phases was counterbalanced.
Table 5

Experiment 3: Error Rates

\begin{tabular}{|c|c|c|c|c|}
\hline \multirow[b]{3}{*}{ Stimulus } & \multicolumn{4}{|c|}{ Face Orientation } \\
\hline & \multicolumn{2}{|c|}{ Upright } & \multicolumn{2}{|c|}{ Inverted } \\
\hline & $M$ & $S E$ & $M$ & $S E$ \\
\hline \multicolumn{5}{|c|}{ Expression Classification } \\
\hline Angry-Female & .03 & .01 & .06 & .02 \\
\hline Angry-Male & .01 & .01 & .02 & .01 \\
\hline Happy-Female & .02 & .01 & .02 & .01 \\
\hline Happy-Male & .04 & .01 & .02 & .01 \\
\hline \multicolumn{5}{|c|}{ Sex Classification } \\
\hline Angry-Female & .25 & .05 & .48 & .02 \\
\hline Angry-Male & .08 & .06 & .36 & .05 \\
\hline Happy-Female & .08 & .06 & .40 & .05 \\
\hline Happy-Male & .08 & .06 & .38 & .05 \\
\hline
\end{tabular}

\section{Results}

\section{Error Rates}

Error proportions for each combination of sex, expression, and face orientation are listed in Table 5. Mean error proportion was significantly higher in the sex classification task $\left(M=.26, M S_{\mathrm{e}}=.03\right)$ than in the expression classification task $\left(M=.026, M S_{\mathrm{e}}=.005\right)[t(36)=7.95, p<$ $.001]$. In the expression classification task, a small and similar error proportion was found for upright faces $(M=$ $\left..025, M S_{\mathrm{e}}=.005\right)$ and inverted faces $\left(M=.028, M S_{\mathrm{e}}=\right.$ $.008)(F<1)$. No further analysis of error rates was performed in the expression task. In the sex classification task, significant main effects were found of orientation $\left[F(1,17)=21.21, p<.001, \eta_{\mathrm{p}}^{2}=.55\right]$, with a higher error proportion to inverted faces $\left(M=.41, M S_{\mathrm{e}}=.03\right)$ than to upright faces $\left(M=.12, M S_{\mathrm{e}}=.04\right)$; of face expression $\left[F(1,17)=14.8, p=.001, \eta_{\mathrm{p}}^{2}=.46\right]$, with more errors to angry than to happy faces; and of face sex $[F(1,17)=$ $11.29, p<.05, \eta_{\mathrm{p}}^{2}=.39$ ], with more errors to feminine than to masculine faces. Of most importance was the significant interaction between face expression and face sex $\left[F(1,17)=19.42, p<.001, \eta_{\mathrm{p}}^{2}=.53\right]$. Post hoc analysis revealed a significantly higher error rate to angry female faces $\left(M=.37, M S_{\mathrm{e}}=.02\right)$ than to happy female faces $\left(M=.24, M S_{\mathrm{e}}=.03\right)$, but no significant differences between angry and happy male faces.

\section{RTs}

RTs for each combination of sex, expression, and face orientation are presented in Figure 4. Mean RTs were significantly faster in the expression classification task $(M=$ 627 msec, $\left.M S_{\mathrm{e}}=30\right)$ than in the sex classification task $\left(M=830 \mathrm{msec}, M S_{\mathrm{e}}=61\right)[t(36)=3.05, p<.05]$. In the expression classification task, a $2 \times 2 \times 2$ repeated measures ANOVA, with orientation, face expression, and face sex as factors, gave significant main effects of the three factors: orientation $\left[F(1,19)=6.83, \eta_{\mathrm{p}}^{2}=.26\right]$, face expression $\left[F(1,19)=8.69, \eta_{\mathrm{p}}^{2}=.31\right]$, and face sex $\left[F(1,19)=7.38, \eta_{\mathrm{p}}^{2}=.28\right]($ all $p \mathrm{~s}<.05)$. As was expected, RTs were slower to inverted faces $\left(M=659, M S_{\mathrm{e}}=34\right)$ than to upright faces $\left(M=595, M S_{\mathrm{e}}=30\right)$. RTs were also slower to angry faces than to happy faces, and to female faces than to male faces. The most important result was, 


\section{A Expression Classification}

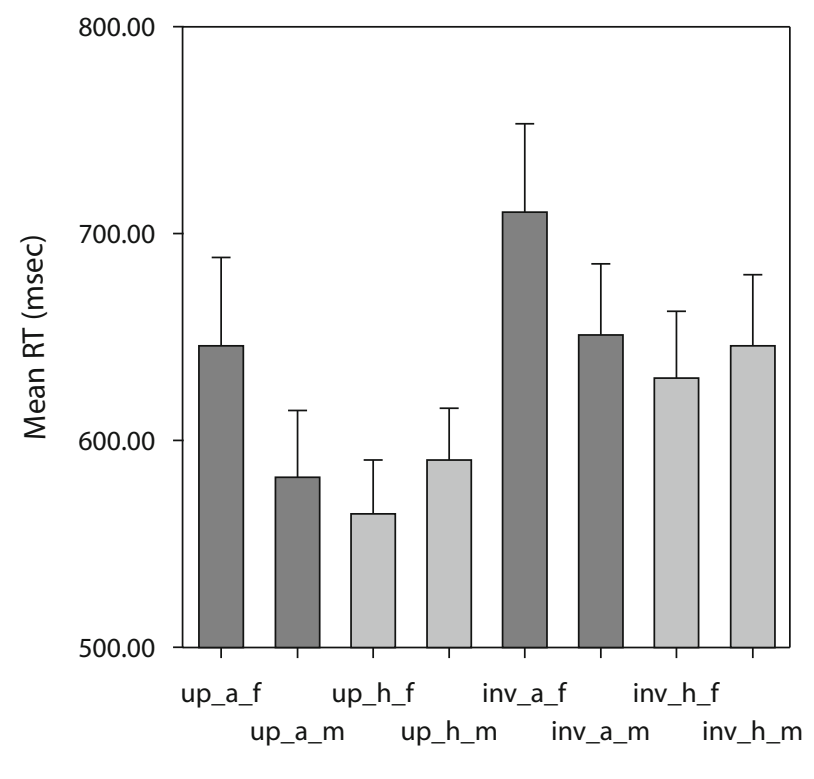

B

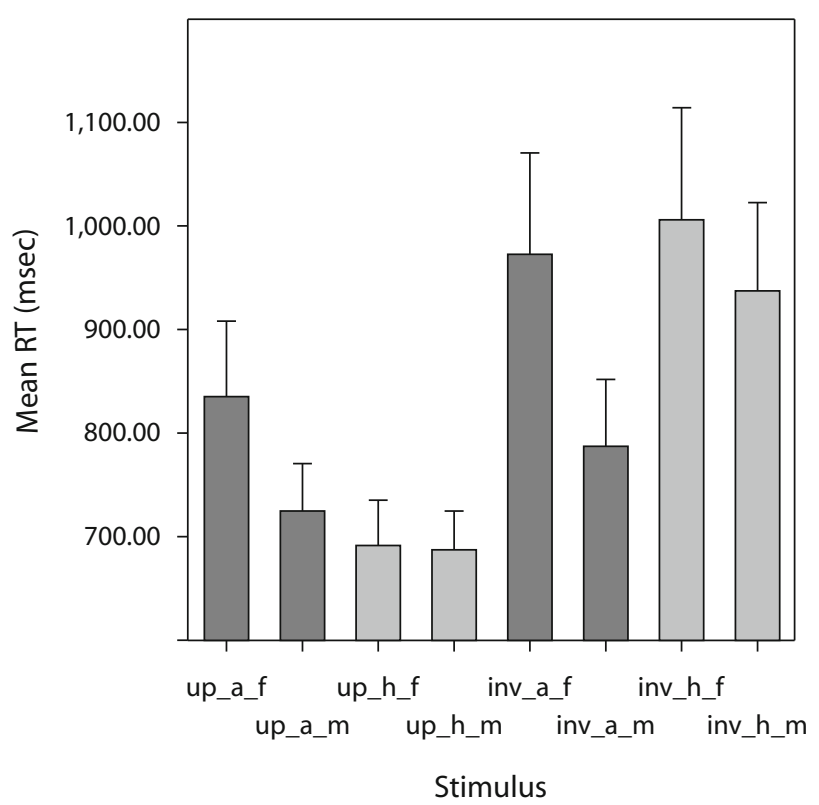

Figure 4. Mean reaction times (RTs) in Experiment 3 for feminine and masculine angry and happy faces. Vertical bars represent the SEM. up, upright; inv, inverted; a, angry; h, happy; f, feminine; m, masculine.

however, that a significant interaction was again found between sex and expression $[F(1,19)=26.6, p<.001$, $\left.\eta_{\mathrm{p}}^{2}=.58\right]$. Post hoc analyses carried out to explore this interaction revealed that angry faces were more rapidly identified as angry when they belonged to a man $(M=$ $\left.616, M S_{\mathrm{e}}=31\right)$ than when they belonged to a woman $\left(M=678, M S_{\mathrm{e}}=39\right)(p<.001)$. The opposite trend was found in the case of happy faces, which were more rapidly identified as happy when they belonged to a woman $(M=$ $\left.596, M S_{\mathrm{e}}=25\right)$ than when they belonged to a man $(M=$ $\left.618, M S_{\mathrm{e}}=26\right)(p<.05)$. The absence of a significant interaction between sex, expression, and orientation means that sex and expression interacted in a similar way with both upright and inverted faces.

In the sex classification task, significant main effects were found of orientation $[F(1,17)=16.16, p=.001$, $\left.\eta_{\mathrm{p}}^{2}=.48\right]$ and of face $\operatorname{sex}\left[F(1,17)=5.11, p<.05, \eta_{\mathrm{p}}^{2}=\right.$ .23]. These effects were due to significantly slower RTs to inverted faces $\left(M=926, M S_{\mathrm{e}}=80\right)$ than to upright faces $\left(M=735, M S_{\mathrm{e}}=48\right)$ and to feminine faces $(M=876$, $\left.M S_{\mathrm{e}}=75\right)$ than to masculine faces $\left(M=784, M S_{\mathrm{e}}=52\right)$. Significant interactions were found between orientation and face expression $\left[F(1,17)=17.06, p=.001, \eta_{\mathrm{p}}^{2}=\right.$ $.50]$, and, most important, between face expression and face $\operatorname{sex}\left[F(1,17)=4.59, p<.05, \eta_{\mathrm{p}}^{2}=.21\right]$. Post hoc tests carried out to explore these interactions revealed, first, that the speed of sex classification was faster for happy faces $\left(M=689, M S_{\mathrm{e}}=40\right)$ than for angry faces $\left(M=780, M S_{\mathrm{e}}=57\right)$, when faces were presented in the upright position $(p<.001)$. However, the opposite was true when the faces were inverted, with faster sex classification of angry faces $\left(M=880, M S_{\mathrm{e}}=72\right)$ than of happy faces $\left(M=971, M S_{\mathrm{e}}=91\right)(p<.05)$. Second, classification of sex was affected by the expression shown by the face. Specifically, angry faces were classified as masculine faster than were happy faces $\left(M=756, M S_{\mathrm{e}}=\right.$ 59 and $M=812, M S_{\mathrm{e}}=58$, respectively) $(p<.05)$. However, although the mean RT was faster to happy feminine than to angry feminine faces, this difference did not reach statistical significance.

\section{Analysis by Items}

These results were confirmed by an analysis across items. In the expression classification condition, this analysis gave significant main effects of orientation $\left[F(1,56)=48.35, p<.001, \eta_{\mathrm{p}}^{2}=.46\right]$, face expression $\left[F(1,56)=18.21 p<.001, \eta_{\mathrm{p}}^{2}=.24\right]$, and face sex $\left[F(1,56)=5.45, p<.05, \eta_{\mathrm{p}}^{2}=.08\right]$. The interaction between face expression and face sex was again significant $\left[F(1,56)=20.6, p<.001, \eta_{\mathrm{p}}^{2}=.26\right]$. In the sex classification condition, significant main effects were found of orientation $\left[F(1,56)=9.56, p<.05, \eta_{\mathrm{p}}^{2}=.14\right]$ and of face $\operatorname{sex}\left[F(1,56)=9.59, p<.003, \eta_{\mathrm{p}}^{2}=.14\right]$. Significant interactions were also found between orientation and face expression $\left[F(1,56)=8.02, p<.05, \eta_{\mathrm{p}}^{2}=.12\right]$ and between face expression and face sex $[F(1,56)=4.59, p<$ $\left..05, \eta_{\mathrm{p}}^{2}=.07\right]$.

\section{Discussion}

In Experiment 3, a face inversion effect was found in the sex classification task, with more errors and slower responses to inverted than to upright faces. In the expression task, upright and inverted faces were responded to with similar accuracy, although inversion did lead to slower classification times. The most important finding of this experiment was that, in spite of these inversion effects, a 
symmetrical interaction between expression and sex was still found, and that the details of this interaction were similar with both upright and inverted faces. Similar to what was found in Experiments 1 and 2, identification of angry expressions was faster for male faces. Conversely, identification of happy expressions was faster for female faces. Sex classification was also influenced by the specific expression shown by the face, and this effect was manifest in both error rates and RTs. However, the interpretation of RT data for inverted faces in the sex classification task must be taken with caution, given that the sample of valid cases was considerably reduced because of a substantial overall error rate in this condition. Male faces were identified as male faster when posing an angry expression. Although an overall trend was found for female faces to be identified faster when posing a happy expression, the difference between angry and happy female faces did not reach statistical significance. However, a significant difference in the same direction between these two conditions was found in error rate, with more errors to angry than to happy faces.

This pattern of results mostly replicates the findings of Experiment 1A, with upright faces, and of Experiment 2, with half-face segments. The fact that the interaction between sex and expression resisted face inversion suggests that it might not be based on configural processes and that it might instead take place at the level of the processing of local features. Although the results of Experiment 2 exclude an interpretation in terms of holistic processing of the whole face (see, e.g., Tanaka \& Farah, 1993), those of Experiment 3 cast some doubt on an interpretation in terms of relational local features, since several findings show that these kinds of features are disrupted by inversion (Leder et al., 2001; Searcy \& Bartlett, 1996). For example, Leder et al. have shown that a specific local relational feature - the interocular distance - is processed differently in inverted than in upright faces. These authors found that judging the interocular distance of two sequentially presented faces was more difficult in inverted presentation. In a similar vein, Searcy and Bartlett found that latencies for detecting spatial alterations in faces were lengthened by inversion more than latencies for detecting alterations in local features. According to these results, one should expect that if a given interaction effect is mediated by relational local features, then it should be either eliminated or in some way disrupted by inversion. The fact that we still found a symmetrical interaction between expression and sex with inverted faces points to a possible role of local features or components of a nonrelational character as the basis for such interaction.

A second relevant result of Experiment 3 was that face inversion had a stronger effect on sex classification than on expression classification. Sex classification suffered more from alteration of the usual presentation of the faces than expression classification. In the expression classification task, the face inversion effect was found only in RTs, since face inversion did not affect response accuracy, which was very high with both orientations. In contrast, face inversion led to a significant and strong increase of errors in the sex classification task. Moreover, face inversion also led to a more pronounced slowing of RTs of correct responses in the sex classification task than in the expression classification task (effect sizes $\eta_{\mathrm{p}}^{2}=.26$ and .48 , for the expression and the sex classification tasks, respectively). The different impact of inversion on the classification of the sex and the expression of faces is suggestive of a different balance in the relative role of configural and local processing in the recognition of these facial properties. To the extent that - as it is usually assumed-face inversion disrupts configural processing, the results of Experiment 3 point to a more important role of this form of processing in sex classification than in expression classification. This does not exclude a significant role for configural processing in expression classification, for which convincing evidence has been presented (Calder et al., 2000), but it shows, at least, that this task can be performed with considerable accuracy, even in conditions in which configural cues are not readily available to the perceiver. In the absence of such cues, it seems that at least some emotional expressions can be identified on the basis of representative local features that are not disrupted by inversion.

An unexpected result of Experiment 3 was the significant interaction between expression and orientation found in the sex classification task. With upright faces, sex was classified faster when the face showed a happy expression - a result that was also found in Experiment 1A. However, with inverted faces, the sex of angry faces was classified faster. One must remember, first, that the high error rate obtained in this condition led to only $59 \%$ of data being valid for RT analysis, thus reducing the representativity of these results. Moreover, the interaction between orientation and expression was found for RTs and not for error rates. In any case, an inspection of Figure 4B indicates that faster recognition of angry faces was, in fact, due to a particularly fast response speed to male faces.

\section{GENERAL DISCUSSION}

The present experiments show a symmetrical interaction between sex and emotional expression in speeded face classification tasks with different conditions of stimulus presentation. In Experiment 1A, whole upright faces were used. Although angry expressions were more rapidly recognized as such in male than in female faces, the opposite was true of happy expressions, which were more rapidly recognized in female than in male faces. Sex classification was, in turn, influenced by expression, with faster recognition of females showing happy rather than angry expressions. However, ratings of the same set of faces on a continuous scale in terms of their perceived expressiveness or masculinity-femininity did not show this interaction. In the two subsequent experiments, sex and expression classification were compared in top and bottom face segments (Experiment 2) and in upright and inverted whole faces (Experiment 3). In Experiment 2, with segmented top and bottom face halves, a symmetrical interaction between sex and expression was again found, although some specific details of the interaction were at variance with those of Experiment 1A. Finally, in Experiment 3, sex and expression 
classifications of upright and inverted faces were compared. In spite of a robust face inversion effect-especially in the case of the sex classification task-a symmetrical interaction between sex and expression was found, with similar characteristics in upright and inverted faces. This is, to our knowledge, the first clear demonstration of a symmetrical interaction between sex and expression in face classification tasks, and one that can be generalized to different conditions of stimulus presentation.

The fact that the interaction between sex and expression appeared with upright faces, segmented half faces, and whole inverted faces, is especially relevant to the identification of potential underlying mechanisms. The present pattern of results is clearly not consistent with an interpretation in terms of holistic processing (Tanaka \& Farah, 1993). This term is usually taken as the equivalent to processing the stimulus as a gestalt, involving mutual interactions between different parts of the face that lead to specific features being perceived differently in the context of the whole face and isolated, as is demonstrated in the composite effect (Calder et al., 2000; Young et al., 1987). First, the results of Experiment 2, with segmented half faces, showed that the interaction between sex and expression appears independently for the upper and lower halves of the face. A second result that argues against a holistic processing explanation is that the interaction between sex and expression was similar for upright and inverted faces (Experiment 3). The disruption of holistic processing has been proposed as a main determinant of the face inversion effect (Farah, Tanaka, \& Drain, 1995). Had the interaction been the product of the irrelevant dimension altering the gestalt or holistic percept of the face, it should have been eliminated or reduced by inversion.

A second variant of configural processing is based on second-order relations, or spatial distances between internal facial features (Diamond \& Carey, 1986). These relational features (e.g., interocular distance or nose-to-mouth distance) are still present in half faces, and there is direct evidence that they can be processed locally, without the presence of a wider face context. For example, Leder et al. (2001) have shown that the discrimination of different interocular distances is independent of the presence of additional face features. However, there is also evidence that the processing of relational local features is disrupted by face inversion (Leder \& Bruce, 2000; Leder et al., 2001; Searcy \& Bartlett, 1996). Given that in Experiment 3 of the present report, the interaction of sex and expression was not affected by inversion, the explanation in terms of relational features seems to lose strength. However, it might still be argued that different relational features might be differently sensitive to disruption by inversion. Below, we will discuss the possible role of brow-to-lid distance-an example of second-order relation between facial features - in the interaction between sex and expression.

A different possibility is that the interaction between sex and expression found in our experiments might have taken place at the level of individual local features that are not disrupted by face inversion. In comparison with faces that vary in relational features, those that vary only in local feature information (e.g., eye or mouth shape) do not show the face inversion effect (see, e.g., Leder \& Bruce, 2000). Thus, the fact that the interaction between sex and expression found in our experiments was not affected by inversion is consistent with an explanation in terms of interaction at the level of individual local features. This explanation might be especially plausible in the case of the influence of expression on sex classification. Facial expressions produce clear distortions in the shape of individual facial features, such as lip raising or eye widening, and some image analysis studies suggest a strong role of shape information for coding facial expression (Calder, Burton, Miller, Young, \& Akamatsu, 2001).

The fact that we found that the interaction between sex and expression is symmetrical is of special importance. Prior research has shown no interference (Le Gal \& Bruce, 2002) or asymmetrical interference from sex to expression classification (Atkinson et al., 2005). Evidence of asymmetrical interactions between invariant and changeable properties of faces has also been obtained in experiments comparing identity and expression classification (Baudouin, Martin, Tiberghien, Verlut, \& Franck, 2002; Schweinberger \& Soukup, 1998). A common aspect of these asymmetrical interactions is that interference was always from the invariant property (i.e., sex or identity) to the changeable property. This has been explained on the assumption that invariant properties of faces provide a reliable basis for processing information about changeable aspects, such as emotional expression (Atkinson et al., 2005). For example, in the case of sex and expression, Atkinson et al. argued that brain systems involved in expression perception might be sensitive to expectations regarding which expressions are more typical in males or in females. However, as long as sex and expression are processed at a similar speed, the same rationale might be equally applied to predict an influence of emotional expression on sex classification. The (learned) expectation that women tend to smile more than men, and that men tend to show angry expressions more often than women (Brody \& Hall, 2000), might also explain why, in our experiments, smiling females were recognized faster as females and angry men were recognized faster as males. Smiling females and angry men would fit to these learned expectations or be closer to the prototypes of female and male faces, respectively. However, this interpretation is not consistent with the finding reported in Experiment $1 \mathrm{~A}$ - that no interaction was found between sex and expression when the participants were asked to rate the expressiveness or the masculinity-femininity of faces on a continuous scale. The fact that the interaction appeared only in a speeded classification task suggests that it might be based in processes acting at the level of perceptual interactions rather than in socially learned expectations or prototypes. However, the influence of expectancies or social stereotypes should not be definitively excluded, given that the analysis of response speed in the masculinity-femininity rating task did reveal an interaction between sex and expression, with faster evaluation of angry males and happy females.

An additional factor that has been proposed to explain asymmetrical interactions is the different processing speed of different properties of faces (see, e.g., Baudouin 
\& Tiberghien, 2002). For this account, given that the sex of faces has been found in some studies to be classified faster than their expression (see, e.g., Atkinson et al., 2005, Experiment 1; Le Gal \& Bruce, 2002, Experiment 2), the influence of sex on expression classification might be simply due to the influence of the fastest process on the slower one. However, asymmetrical interactions have been found even when steps have been taken to equate sex and expression classification in difficulty (Atkinson et al., 2005, Experiment 2). The present series of experiments confirms that the interaction between sex and expression cannot be explained by differences in processing speed. First, the interaction appeared even though sex and expression were classified at similar speeds in Experiments 1A and 2. Moreover, in Experiment 3, an influence of sex on expression classification was found in spite of sex being classified at a significantly lower speed than expression. The very fact that sex influenced expression classification under these circumstances might seem counterintuitive at first sight, because it appears as if sex can influence expression classification even before it has been itself recognized. This apparent contradiction can be solved on the assumption that what influences expression classification is not sex in itself, but some specific facial feature that covaries with sex categories and that is processed before the cognitive system has gathered perceptual evidence enough to allow explicit identification of sex.

Contrary to what would have been expected from the independent route hypothesis (Bruce \& Young, 1986), the results from the present series of experiments indicate that emotional expression was not ignored while speeded sex classification was performed and that, complementarily, sex was not ignored while expression was classified. In both cases, the irrelevant dimension had a clear effect on classification performance. Our results, thus, seem more consistent with recent proposals that have questioned the validity of the traditional approach to face recognition, in terms of independent visual pathways for processing different properties of faces (see, e.g., Calder \& Young, 2005; Ganel \& Goshen-Gottstein, 2002). For example, after reviewing the relevant evidence, Calder and Young concluded that there is no strong support for the hypothesis of independent systems for the processing of identity and expression, and they proposed, as a viable alternative, an approach based on image analysis. This approach, which applies the statistical technique of principal component analysis (PCA) to image analysis (Calder et al., 2001), allows coding of several facial properties by a single mechanism in terms of partially independent sets of dimensions, without the need of segregation into different processing routes. Following this approach, what our results suggest is a partial overlapping between the relevant dimensions for coding sex and expression. And if, as suggested by some recent findings, sex and identity cannot be dissociated (see, e.g., Ganel \& Goshen-Gottstein, 2002), this interpretation of our results is consistent with the arguments put forward by Calder and Young regarding the relationships between identity and expression.
A symmetrical interaction between sex and expression can be understood under the assumption that coding of these facial properties is not completely independent, both logically (i.e., in terms of the information from which each categorization is derived) and functionally. Interaction can be expected if sex and expression classification rely, in part, on a common set of facial features that are diagnostic for both classification tasks and that are processed by a single system or by interconnected parallel systems. As long as the specific values of a feature diagnostic for both sex and expression classification vary independently for each of these facial properties, interaction can be expected. If a specific value, or range of values, of that feature is typical of a sex category and of an emotional category (e.g., men and anger), then exemplars belonging to both categories will be recognized faster than those belonging to categories in which the typical values of the feature diverge (e.g., women and anger).

A clear example of a feature that has diagnostic value for both sex and expression classification is that of browto-lid distance. Facial measurement and behavioral studies have shown that the vertical distance between the eyebrow and the upper eyelid is one of the most reliable cues to sex discrimination from static face images (Burton et al., 1993; Campbell et al., 1996). Brow-to-lid distance is, on average, smaller in males than in females, and is a good discriminator between male and female faces (Burton et al., 1993). Moreover, brow-to-lid distance is a potent cue for the identification of some facial expressions, such as anger and surprise. Specifically, lowering of the eyebrows and pulling them together is one of the action units that are characteristic of angry expressions (Ekman \& Friesen, 1978; Gosselin et al., 1997). The different typical values of brow-to-lid distance in female faces and in angry expressions might easily explain the higher error proportion and slower identification of sex in female angry faces found in the present series of experiments. However, we cannot at present provide a plausible explanation of the differences found in the case of happy faces, beyond pointing out that complete happy expressions involve changes in the eye and mouth areas (Ekman \& Friesen, 1982), both of which have been found to be determinant for sex discrimination (Brown \& Perrett, 1993).

One last result from the present series of experiments that is worth commenting on is the different sensitivity of sex and expression classification to face segmentation and face inversion. Although error rates were higher in the sex classification task in all three experiments, this difference was especially strong in Experiments 2 and 3. Although there is convincing evidence for the role of configural processes in both sex and expression classification (Baudouin \& Humphreys, 2006; Calder et al., 2000), this difference seems to suggest a stronger role for configural processing in the case of sex classification. In the case of segmented faces, the higher error rate in sex classification might be explained by the fact that sex recognition depends on a wider set of features than does recognition of emotional expression. Although 
recognition of emotional expression is based on facial changes produced by action units performed by muscles in the eye and mouth regions (Ekman \& Friesen, 1978), sex identification depends on a vast array of external and internal facial features, including hairstyle, face shape, 3-D distances, skin texture, and internal local and relational features (Brown \& Perrett, 1993; Burton et al., 1993). In the absence of the context of the whole face, sex classification of face segments with alterations in the shape of local features or in the relations between them produced by emotional expression should be especially difficult. On the contrary, the fact that identification of expression is still highly accurate when only information from the top or bottom segments of the face is available suggests that this task relies more on distinctive local features present in the upper or the lower face.

A shortcoming of the present series of experiments is that males and females were unequally represented in the sample, with a majority of female participants. However, it is not clear to what extent this characteristic of the sample might have determined the pattern of results we obtained. For example, although there have been reports showing that women outperform men in decoding emotional expression (Hall, 1978; Rotter \& Rotter, 1988), this difference has not always been found. Two recent articles in which an interaction between sex of the participant and classification of sex and expression was not found are those of Penton-Voak, Allen, Morrison, Gralewski, and Campbell (2007), with sex classification, and of Arcuri, Castelli, Boca, Lorenzi-Cioldi, and Dafflon (2001), who used a category verification procedure with sex and expression as categories. In the case of sex classification, it is not clear that differences exist in how accurately male and female observers classify the gender of a face depending on its sex. For example, O'Toole et al. (1998) did not find an interaction of participant sex and stimulus sex in the accuracy of sex classification.

The present series of experiments has provided clear evidence of a symmetrical interaction between sex and expression in speeded face classification. The fact that the irrelevant property influenced performance in both classification tasks is not consistent with the traditional view of face perception, which postulates independent routes for the processing of different facial properties (Bruce \& Young, 1986). Overall, the results agree more with recent evidence of interaction between different face properties in attentional and categorization tasks and with recent proposals, such as that advanced by Calder and Young (2005), who proposed a single mechanism for extracting different facial properties from a single visual representation. However, the fact that we used only happy and angry expressions leaves open the question of the generality of our findings. It might well be that the precise relation between sex and expression would depend on the specific expression tested and that different features that are distinctive of different expressions interact in different ways with the sex of the face.

Note-Accepted by the previous editorial team, when Thomas H. Carr was Editor.

\section{AUTHOR NOTE}

This research was supported by Research Grant SEJ-2006-01576 PSIC from the Spanish Ministerio de Ciencia y Tecnología. We thank Daniel Medina, Sonia Rodriguez, and Francisco Javier Román for their help with recruiting the participants and running the experiments. Address correspondence to L. Aguado, Facultad de Psicología, Campus de Somosaguas, 28223, Madrid, Spain (e-mail: laguado@psi.ucm.es).

\section{REFERENCES}

Arcuri, L., Castelli, L., Boca, S., Lorenzi-Cioldi, F., \& Dafflon, A.-C. (2001). Fuzzy gender categories: How emotional expression influences typicality. Swiss Journal of Psychology, 60, 179-191.

Atkinson, A. P., Tipples, J., \& Burt, D. M., \& Young, A. W. (2005). Asymmetric interference between sex and emotion in face perception. Perception \& Psychophysics, 67, 1199-1213.

Bassili, J. N. (1979). Emotion recognition: The role of facial movement and the relative importance of upper and lower areas of the face. Journal of Personality \& Social Psychology, 37, 2049-2058.

Baudouin, J.-Y., \& HumPhreYs, G. W. (2006). Configural information in gender categorisation. Perception, 35, 531-540.

Baudouin, J.-Y., Martin, F., Tiberghien, G., Verlut, I. \& Franck, N. (2002). Selective attention to facial emotion and identity in schizophrenia. Neuropsychologia, 40, 503-511.

Baudouin, J.-Y., \& Tiberghien, G. (2002). Gender is a dimension of face recognition. Journal of Experimental Psychology: Learning, Memory, \& Cognition, 28, 362-365.

Brody, L. R., \& HaLl, J. A. (2000). Gender, emotion, and expression. In M. Lewis \& J. M. Haviland-Jones (Eds.), Handbook of emotions (2nd ed., pp. 338-349). New York: Guilford.

Brown, E., \& Perrett, D. I. (1993). What gives a face its gender? Perception, 22, 829-840.

Bruce, V., Burton, A. M., Hanna, E., Healey, P., Mason, O. Coombes, A., ET AL. (1993). Sex discrimination: How do we tell the difference between male and female faces? Perception, 22, 131-152.

Bruce, V., \& Young, A. (1986). Understanding face recognition. British Journal of Psychology, 77, 305-327.

Bruyer, R., Laterre, C., Seron, X., Feyereisen, P., Strypstein, E., Pierrard, E., \& Rectem, D. (1983). A case of prosopagnosia with some preserved covert remembrance of familiar faces. Brain \& $\mathrm{Cog}$ nition, 2, 257-284.

Burton, A. M., Bruce, V., \& Dench, N. (1993). What's the difference between men and women: Evidence from facial measurement. Perception, 22, 153-176.

Calder, A. J., Burton, A. M., Miller, P., Young, A. W., \& AkaMATSU, S. (2001). A principal component analysis of facial expressions. Vision Research, 41, 1179-1208.

CAlder, A. J., \& Young, A. W. (2005). Understanding the recognition of facial identity and facial expression. Nature Reviews Neuroscience, 6, 641-651.

Calder, A. J., Young, A. W., Keane, J., \& Dean, M. (2000). Configural information in facial expression perception. Journal of Experimental Psychology: Human Perception \& Performance, 26, $527-551$

Campbell, R., Wallace, S., \& Benson, P. J. (1996). Real men don't look down: Direction of gaze affects sex decisions on faces. Visual Cognition, 3, 393-412.

DiAMOND, R., \& CAREY, S. (1986). Why faces are and are not special: An effect of expertise. Journal of Experimental Psychology: General, 115, 107-117.

Dubois, S., Rossion, B., Schiltz, C., Bodart, J. M., Michel, C., Bruyer, R., \& Crommelinck, M. (1999). Effect of familiarity on the processing of human faces. NeuroImage, 9, 278-289.

Ekman, P., \& Friesen, W. V. (1976). Pictures of facial affect. Palo Alto, CA: Consulting Psychologists Press.

EkMAN, P., \& Friesen, W. V. (1978). Facial action coding system: A technique for the measurement of facial movement. Palo Alto, CA: Consulting Psychologists Press.

Ekman, P., \&, Friesen, W. V. (1982). Felt, false, and miserable smiles. Journal of Nonverbal Behavior, 6, 238-252.

Ellis, A. W., Young, A. W., \& Flude, B. M. (1990). Repetition priming and face processing: Priming occurs within the system that responds 
to the identity of a face. Quarterly Journal of Experimental Psychology, 42A, 495-512.

Ellison, J. W., \& Massaro, D. W. (1997). Featural evaluation, integration, and judgment of facial affect. Journal of Experimental Psychology: Human Perception \& Performance, 23, 213-226.

Farah, M. J., TanaKa, J. W., \& Drain, H. M. (1995). What causes the inversion effect? Journal of Experimental Psychology: Human Perception \& Performance, 21, 628-634.

Fox, E., Lester, V., Russo, R., Bowles, R. J., Pichler, A., \& DutTON, K. (2000). Facial expressions of emotion: Are angry faces detected more efficiently? Cognition \& Emotion, 14, 61-92.

Ganel, T., \& Goshen-GotTstein, Y. (2002). Perceptual integrality of sex and identity of faces: Further evidence for the single-route hypothesis. Journal of Experimental Psychology: Human Perception \& Performance, 28, 854-867.

Ganel, T., \& Goshen-Gottstein, Y. (2004). Effects of familiarity on the perceptual integrality of the identity and expression of faces: The parallel-route hypothesis revisited. Journal of Experimental Psychology: Human Perception \& Performance, 30, 583-597.

Ganel, T., Valyear, K. F., Goshen-Gottstein, Y., \& Goodale, M. A (2005). The involvement of the "fusiform face area" in processing facial expression. Neuropsychologia, 43, 1645-1654.

GARNER, W. R. (1976). Interaction of stimulus dimensions in concept and choice processes. Cognitive Psychology, 8, 98-123.

Goshen-Gottstein, Y., \& Ganel, T. (2000). Repetition priming for familiar and unfamiliar faces in a sex-judgment task: Evidence for a common route for the processing of sex and identity. Journal of Experimental Psychology: Learning, Memory, \& Cognition, 26, 1198-1214.

Gosselin, P., Kirouac, G., \& Doré, F. Y. (1997). Components and recognition of facial expression in the communication of emotion by actors. In P. Ekman \& E. L. Rosenberg (Eds.), What the face reveals: Basic and applied studies of spontaneous expression using the facial action coding system (FACS) (pp. 243-267). Oxford: Oxford University Press.

Hall, J. A. (1978). Gender effects in decoding nonverbal cues. Psychological Bulletin, 85, 845-857.

Haxby, J. V., Hoffman, E. A., \& Gobbini, M. I. (2000). The distributed human neural system for face perception. Trends in Cognitive Sciences, 4, 223-233.

Hess, U., Blairy, S., \& KLECK, R. E. (1997). The intensity of emotional facial expressions and decoding accuracy. Journal of Nonverbal Behavior, 21, 241-257.

Hoss, R. A., Ramsey, J. L., Griffin, A. M., \& Langlois, J. H. (2005) The role of facial attractiveness and facial masculinity/femininity in sex classification of faces. Perception, 34, 1459-1474.

LEDER, H., \& BRUCE, V., (2000). When inverted faces are recognized: The role of configural information in face recognition. Quarterly Journal of Experimental Psychology, 53A, 513-536.

Leder, H., Candrian, G., Huber, O., \& Bruce, V. (2001). Configural features in the context of upright and inverted faces. Perception, 30, 73-83.

Le Gal, P. M., \& Bruce, V. (2002). Evaluating the independence of sex and expression in judgments of faces. Perception \& Psychophysics, 64, 230-243.

LUNDQVIST, D., \& LiTTON, J. E. (1998). The averaged Karolinska directed emotional faces - AKDEF [CD-ROM]. Stockholm: Karolinska Institutet, Department of Clinical Neuroscience, Psychology Section.
Maurer, D., Le Grand, R., Mondloch, C. J. (2002). The many faces of configural processing. Trends in Cognitive Sciences, 6, 255-260.

McKelvie, S. J. (1995). Emotional expression in upside-down faces: Evidence for configurational and componential processing. British Journal of Social Psychology, 34, 325-334.

Narumoto, J., Okada, T., Sadato, N., Fukui, K., \& Yonekura, Y. (2001). Attention to emotion modulates fMRI activity in human right superior temporal sulcus. Cognitive Brain Research, 12, 225-231.

O’Toole, A. J., Deffenbacher, K. A., Valentin, D., McKee, K., HuFF, D., \& ABDI, H. (1998). The perception of face gender: The role of stimulus structure in recognition and classification. Memory \& Cognition, 26, 146-160.

Penton-Voak, I. S., Allen, T., Morrison, E. R., Gralewski, L., \& Campbell, N. (2007). Performance on a face perception task is associated with empathy quotient scores, but not systemizing scores or participant sex. Personality \& Individual Differences, 43, 2229-2236.

Rotter, N. G., \& Rotter, G. S. (1988). Sex differences in the encoding and decoding of negative facial emotions. Journal of Nonverbal Behavior, 12, 139-148.

Schweinberger, S. R., \& Soukup, G. R. (1998). Asymmetric relationships among perceptions of facial identity, emotion, and facial speech. Journal of Experimental Psychology: Human Perception \& Performance, 24, 1748-1765.

SEARCY, J. H., \& Bartlett, J. C. (1996). Inversion and processing of component and spatial-relational information in faces. Journal of Experimental Psychology: Human Perception \& Performance, 22, 904-915.

Serrano-Pedraza, I., \& Sierra-Vázquez, V. (2006). The effect of white-noise mask level on sinewave contrast detection thresholds and the critical-band-masking model. Spanish Journal of Psychology, $\mathbf{9}$, 249-262.

TANAKA, J. W., \& FARAH, M. J. (1993). Parts and wholes in face recognition. Quarterly Journal of Experimental Psychology, 46A, 225-245.

Tipples, J., AtKinson, A. P., \& Young, A. W. (2002). The eyebrow frown: A salient social signal. Emotion, 2, 288-296.

Tranel, D., Damasio, A. R., \& Damasio, H. (1988). Intact recognition of facial expression, gender, and age in patients with impaired recognition of face identity. Neurology, 38, 690-696.

VALENTINE, T. (1988). Upside-down faces: A review of the effect of inversion upon face recognition. British Journal of Psychology, 79, 471-491.

Winston, J. S., Henson, R. N. A., Fine-Goulden, M. R., \& Dolan, R. J. (2004). fMRI-adaptation reveals dissociable neural representations of identity and expression in face perception. Journal of Neurophysiology, 92, 1830-1839.

YIN, R. K., (1969). Looking at upside-down faces. Journal of Experimental Psychology, 81, 141-145.

Young, A. W., Hellawell, D., \& Hay, D. C. (1987). Configurational information in face perception. Perception, 16, 747-759.

Young, A. W., McWeeny, K. H., Hay, D. C., \& Ellis, A. W. (1986). Matching familiar and unfamiliar faces on identity and expression. Psychological Research, 48, 63-68.

\section{NOTE}

1. We thank an anonymous reviewer for suggesting this possibility. 
APPENDIXA

Pictures Used in Experiments 1A, 2, and 3

\begin{tabular}{|c|c|c|c|c|c|c|c|}
\hline $\begin{array}{l}\text { Picture } \\
\text { Code }\end{array}$ & $\begin{array}{c}\text { Image } \\
\text { Collection }\end{array}$ & Expression & Sex & $\begin{array}{c}\text { Picture } \\
\text { Code }\end{array}$ & $\begin{array}{c}\text { Image } \\
\text { Collection }\end{array}$ & Expression & Sex \\
\hline AF07ANS & KDEF & angry & $\mathrm{F}$ & AM03ANS & KDEF & angry & $\bar{M}$ \\
\hline BF26ANS & KDEF & angry & $\mathrm{F}$ & BM17ANS & KDEF & angry & M \\
\hline AF14ANS & KDEF & angry & $\mathrm{F}$ & AM05ANS & KDEF & angry & M \\
\hline IMG0089 & POFA & angry & $\mathrm{F}$ & AM09ANS & KDEF & angry & M \\
\hline AF35ANS & KDEF & angry & $\mathrm{F}$ & AM10ANS & KDEF & angry & M \\
\hline AF31ANS & $\mathrm{KDEF}$ & angry & $\mathrm{F}$ & BM15ANS & $\mathrm{KDEF}$ & angry & $\mathrm{M}$ \\
\hline BF16ANS & KDEF & angry & F & IMG0106 & POFA & angry & M \\
\hline IMG0096 & POFA & angry & $\mathrm{F}$ & BM21ANS & KDEF & angry & M \\
\hline AF19HAS & KDEF & happy & $\mathrm{F}$ & AM07HAS & KDEF & happy & $\mathrm{M}$ \\
\hline BF04HAS & KDEF & happy & $\mathrm{F}$ & AM22HAS & KDEF & happy & M \\
\hline AF11HAS & KDEF & happy & $\mathrm{F}$ & BM29HAS & KDEF & happy & M \\
\hline AF25HAS & KDEF & happy & $\mathrm{F}$ & BM12HAS & KDEF & happy & M \\
\hline AF02HAS & KDEF & happy & $\mathrm{F}$ & AM13HAS & KDEF & happy & M \\
\hline AF01HAS & $\mathrm{KDEF}$ & happy & $\mathrm{F}$ & AM11HAS & KDEF & happy & M \\
\hline AF27HAS & KDEF & happy & $\mathrm{F}$ & AM23HAS & KDEF & happy & M \\
\hline BF28HAS & KDEF & happy & $\mathrm{F}$ & AM16HAS & KDEF & happy & M \\
\hline
\end{tabular}

Note-Picture codes are given as they appear in the KDEF (Karolinska Directed Emotional Faces; Lundqvist \& Litton, 1998) and POFA (Pictures of Facial Affect; Ekman \& Friesen,1976).

\section{APPENDIX B}

\section{Procedure Used to Construct the Images With a Desired $\mathbf{c}_{\mathrm{RMS}}$}

In order to construct the images with a desired $\mathrm{c}_{\mathrm{RMS}}$ (root mean square contrast), we followed these steps: First, we cut out the original images $(562 \times 762$ pixels, horizontal $\times$ vertical $)($ see Figures $1 \mathrm{~A}$ and $1 \mathrm{~B})$ of the faces to remove most of the hair and to make the image square $(512 \times 512$ pixels $)$, subtending an area of $13.5^{\circ} \times 13.5^{\circ}$. Second, we added to the square image an oval window subtending an area of $7.95^{\circ} \times 12.3^{\circ}$ (see Figure 1C). Third, we let $I$ be the square digital image of dimensions $N R \times N C$ pixels and 256 gray levels. Then, in order to construct a new image, $J$, in which the mean of the gray levels was equal to 128 , we proceeded as follows:

$$
J(i, j)=128\left[1+\left(\left(\frac{I(i, j)}{\sum \sum I(i, j) /(N R \times N C)}\right)-1\right)\right] .
$$

Fourth, the image $J$ presented on the screen was

$$
L(x, y)=L_{0}\left[1+m\left(\frac{J(i, j)}{128}-1\right)\right]
$$

where $L_{0}$ is the mean luminance in $\mathrm{cd} / \mathrm{m}^{2}$, and $m$ is the contrast of the image. Note that by manipulating the value of $m$, we change the $\mathrm{c}_{\mathrm{RMS}}$ of the image.

Fifth, we wanted to present on the screen all images with a fixed $c_{R M S}\left(c_{R M S}=0.2\right)$; then, we needed to obtain the specific value of $m$ for each image (see Figure 1D). The equation (Serrano-Pedraza \& Sierra-Vázquez, 2006) used to obtain $m$ was

$$
m=\frac{128 \mathrm{c}_{\mathrm{RMS}}}{\sqrt{a-b^{2}}+\mathrm{c}_{\mathrm{RMS}}(128-b)} \quad 0<m<1
$$

where

$$
a=\sum \sum J^{2}(i, j) /(N R \times N C), \text { and } b=\sum \sum J(i, j) /(N R \times N C) .
$$

